\title{
Erratum to: Bilateral Clubfeet Are Highly Correlated: A Cautionary Tale for Researchers
}

\author{
Kelly Gray B App Sc, Paul Gibbons MBBS, \\ David Little MBBS, PhD, Joshua Burns PhD
}

Published online: 3 September 2014

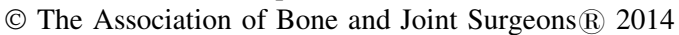

\section{Erratum to: Clin Orthop Relat Res DOI 10.1007/s11999-014-3776-6}

The article "Bilateral Clubfeet Are Highly Correlated: A Cautionary Tale for Researchers" (Clin Orthop Relat Res 2014, epub ahead of print, DOI 10.1007/s11999-014-3776-6) contained important areas of overlap with the article "Unilateral Versus Bilateral Clubfoot: An Analysis of Severity and Correlation," which was published in a volume of the Journal of Pediatric Orthopaedics (British)

Each author certifies that he or she, or a member of his or her immediate family, has no funding or commercial associations (eg, consultancies, stock ownership, equity interest, patent/licensing arrangements, etc) that might pose a conflict of interest in connection with the submitted article.

All ICMJE Conflict of Interest Forms for authors and Clinical Orthopaedics and Related Research editors and board members are on file with the publication and can be viewed on request.

Each author certifies that his or her institution approved the human protocol for this investigation, that all investigations were conducted in conformity with ethical principles of research, and that informed consent for participation in the study was obtained.

The online version of the original article can be found under doi:10.1007/s11999-014-3776-6.

\section{K. Gray $(\square)$}

Physiotherapy Department, The Children's Hospital at

Westmead, Locked Bag 4001, Westmead, Sydney, NSW 2145,

Australia

e-mail: kelly.gray@health.nsw.gov.au

P. Gibbons, D. Little

Department of Orthopaedic Surgery, The Children's Hospital at

Westmead, Sydney, NSW, Australia
(2014, 23:397-399). This was not made clear in the $C O R R^{\circledR}$ article. In particular, 26 of the 33 patients whose data were included in the study published in $C O R R^{\circledR}$ were included in the earlier work published in Journal of Pediatric Orthopaedics (British). This is particularly relevant to the question of clubfoot severity at the time of patient presentation, which was studied in both papers.

The authors regret that they did not make this clear in the later publication in $C O R R^{\circledR}$. 